mented, ${ }^{3}$ reflecting the reliable bioavailability with this route. Although direct comparison with oral indomethacin has not been undertaken, intravenous indomethacin appears to be at least as well tolerated and should be preferred for the treatment of patent ductus arteriosus.

1 Clyman RI, Heymann MA. Pharmacology of the ductus arteriosus. Pediatr Clin North Am 1981;28:77-93.
2 Vert P, Bianchetti G, Marchal F, Monin P, Morselli PL. Effectiveness and pharmacokinetics of indomethacin in premature newborns with patent ductus arteriosus. Eur 7 Clin Pharmacol 1980;18:83-8.

3 Merritt TA, Bejar R, Corazza M, Ikonen RS, Davis R, Rosenberg M. Clinical trials of intravenous indomethacin for closure of the patent ductus arteriosus. Pediatr Cardiol 1983;4:71-9.

4 Del Favero A. Side effects of drugs annual 10. Amsterdam: Elsevier, 1986:80-1. 5 Corazza MS, Davis RF, Merritt TA, Bejar R, Cvetnic W. Prolonged bleeding time in preterm infants receiving indomethacin for patent ductus arteriosus. I Pediatr 1984;105:292-6.

(Accepted 24 May 1988)

\section{Maternal age, illegitimacy, and postneonatal mortality}

\section{R R Gordon, R Sunderland}

Gosfield Hall, Near Halstead, Essex CO9 1SF R R Gordon, FRCP, retired consultant paediatrician

Selly Oak Hospital, Birmingham B296JD

$\mathrm{R}$ Sunderland, $\mathrm{MD}$, consultant paediatrician

Correspondence to: $\mathrm{Dr}$ Gordon.
Postneonatal mortality is widely used as an indicator of infant health, although positive proof of a correlation is lacking; this variable has the advantage of being consistently recorded nationally. In the first 75 years of this century, when the major registered causes of postneonatal death were infections, postneonatal mortality was regarded as an indicator of associated social conditions. Nowadays the main causes of postneonatal death are the sudden infant death syndrome $(43 \cdot 8 \%)$ and congenital anomalies (18.5\%); infections of all
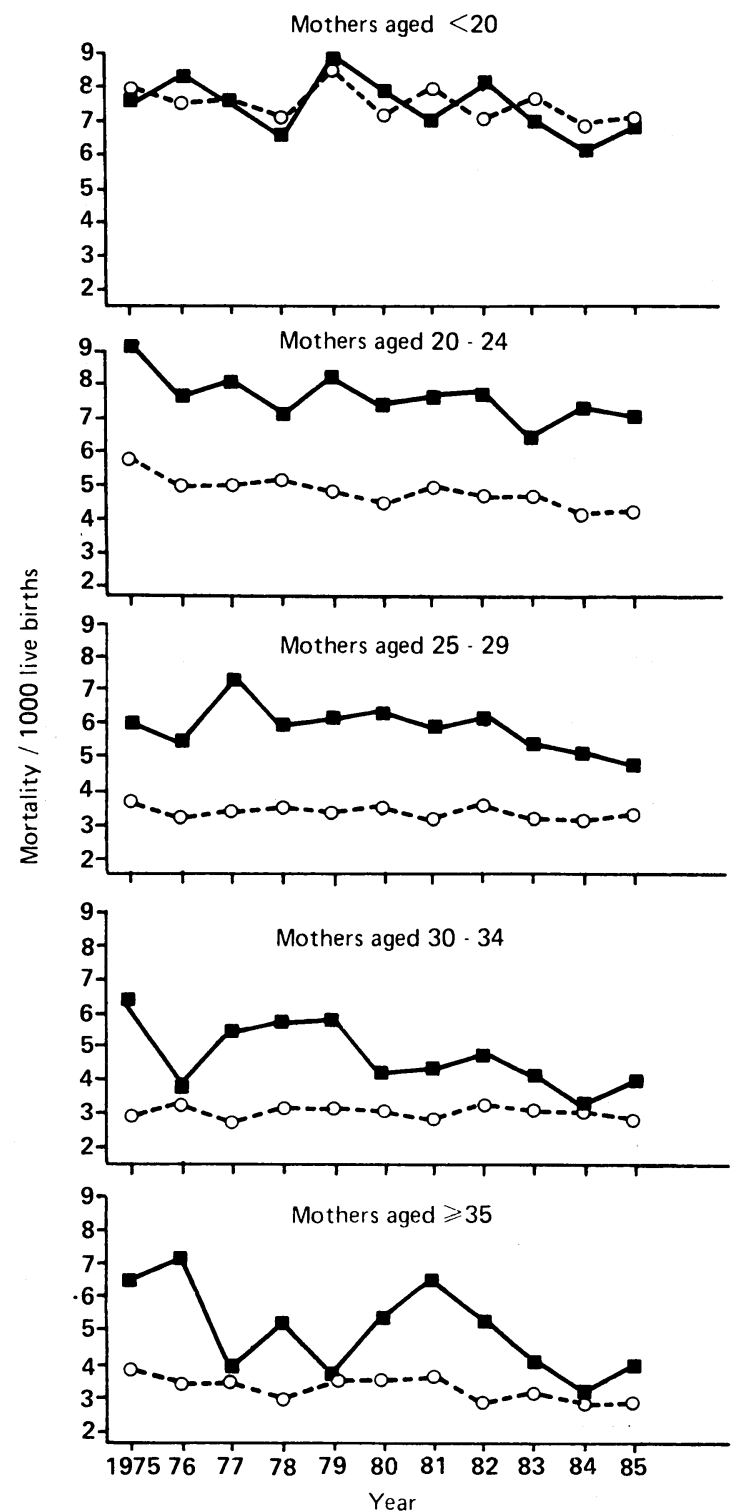

kinds now account for only $16.4 \%$, and there is debate over whether some deaths registered as due to respiratory infections may in fact have been due to the sudden infant death syndrome..$^{1-4}$ Congenital anomalies alone show no social gradient. While seeking aetiological mechanisms for differences in postneonatal mortality we examined their relation to maternal age and illegitimacy.

\section{Methods and results}

All data were derived from tables compiled by the Office of Population Censuses and Surveys listing postneonatal mortality during $1975-85$. The numbers of legitimate and illegitimate live births were obtained from Fertility Trends (series FM1) and details on postneonatal mortality from the $\mathrm{DH} 3$ series. The figure shows that for all maternal ages beyond 20 the postneonatal mortality among illegitimate babies was consistently higher than that among legitimate babies. For teenage mothers, however, the rates were the same but at the high level seen among illegitimate babies.

\section{Comment}

Since Victorian times illegitimate babies have been known to have a reduced chance of survival. Traditional arguments relating to poverty and lack of access to medical care became less relevant with the advent of the welfare state, yet the difference persists. The exact cause is unclear but must lie within the plethora of circumstances classed as social. The rising illegitimacy rate may have contributed to the recent rise in postneonatal mortality in the United Kingdom. Since 1975 there has been a consistent increase (from $9 \%$ to $19 \%$ ) in the proportion of illegitimate live births in England and Wales. Sixty five per cent of all babies born to mothers aged under 20 are now illegitimate. Many of these mothers live in inner cities, and this trend, which does not seem to be related to failure of contraception, may have serious implications for the NHS.

This study found that legitimate babies born to young mothers are also at increased risk of postneonatal death. This finding conflicts with data from a Swedish study of the sudden infant death syndrome, ${ }^{5}$ but the number of married mothers under 20 in that study was small and the incidence of the syndrome in Sweden subsequently rose. The increased risk of postneonatal death among babies of young mothers (married or not) may be due to lack of maternal skills or support; perhaps the educational priorities for teenagers should be reappraised.

\footnotetext{
Keeling JW, Golding J, Sutton B. Identification of cases of sudden infant death syndrome from death certificates. If Epidemiol Community Health 1985;39:148-51.

2 Madeley RJ, Hull D, Holland T. Prevention of postneonatal mortality. Arch Dis Child 1986;61:459-63.

Gordon RR. Whatever happened to the Black report? Br Med f 1986:293:758-9. 4 Sunderland R, Sunderland EP. Invalid certification of young deaths. Arch Dis Child 1983,58:867-74.

5 Norvenius SG. Sudden infant death syndrome in Sweden in 1973-77 and 1979. Acta Paediatr Scand [Suppl] 1987;333:1-138.

(Accepted 24 May 1988)
} 